Canadian Journal of Family and Youth, 8(1), 2016, pp 173-203

ISSN 1718-9748 () University of Alberta

http://ejournals.library.ualberta.ca/index/php/cjfy

\title{
Why Some Children Come to School with "Baggage": The Effects of Trauma Due to Poverty, Attachment Disruption and Disconnection on Social Skills and Relationships
}

\author{
Irene G. Wilkinson
}

\begin{abstract}
Children living in adverse conditions of poverty and/or abuse or in institutional or foster care, suffer physiological changes in their developing brains which negatively affect their social skills and therefore their ability to socialize and form meaningful connections with others. Impeded social skills development also interferes with children's ability to demonstrate self-control, to learn and to demonstrate appropriate behaviour. Their physical and emotional health and wellbeing also suffer. Without greater understanding, intervention and support from schools, the future for these children continues to look extremely bleak. The emotional and social costs are high. This paper looks at the effects of trauma due to poverty, parent-child separation (attachment disruption) and disconnection on social skills development in children and the reasons why some children who have experienced adversity early in their lives, come to school with "baggage". It takes a cursory look at the effects of emotional trauma on the developing brain and examines why affected children often demonstrate anti-social behaviour and struggle with forming meaningful relationships and learning in school. Also considered are the problems encountered by some children at the upper end of the socioeconomic spectrum, most particularly their difficulties making friends.
\end{abstract}

\footnotetext{
Although her formal qualifications are in biomedical science (her thesis on methods for demonstrating changes in the lining cells of the human larynx won her a Fellowship of the Institute of Biomedical Sciences in 1973), in addition to cancer research, Irene Gregory Wilkinson has worked for much of her life in fine and performing arts, broadcasting and in educational and social skills support for children at risk. Although "retired", Irene is still busy writing and presenting papers to schools on the dangers of smoking, the power of music in learning and enhancing relationships, the importance of forging meaningful connections with others and the school family and getting along. She continues her research and writing on the aetiology of bullying and other forms of anti-social behaviour, and to pursue ways of accommodating and mitigating these behaviours by creating communities of compassion and caring. Publications include: Watt, J., Gregory, Irene \& Stell, P.M. (1975). An Alcian Blue/Phloxine Method for the Gross Demonstration of Squamous Metaplasia in the Larynx. Journal of Pathology, 116 (1), 31-36; Stell, P.M., Gregory, Irene \& Watt, J. (1980). Morphology of the Human Larynx. II The Subglottis. Clinical Otolaryngology and Allied Sciences, 5 (6), 389-395; and Wilkinson, I.G., (2013). Let There Be Music: Making a case for using music in schools to enhance relationships and readiness for learning. Canadian Music Educators' Journal, 55 (1), 28-31.
} 
Wilkinson

\section{Introduction}

It is well known that adverse childhood experiences, poor nurturing and lack of sensory input during early child development, inhibit brain development and assault or interrupt normal childhood development processes in a variety of ways (Anda, Felitti, Bremner, Walker, Whitfield, Perry, Dube, \& Giles, 2006; Watt, Ayoub, Bradley \& Puma, 2008). Children who have experienced adverse effects due to poverty, families without permanent homes or jobs, family violence, poor modelling, absent or unavailable parents and maternal deprivation (leading to attachment disruption), are, often, the children who find it hard to make connections with others. Social skills have been found to be markedly absent in these children (Heckman, 2008; Moroz, 2005). Deficits in social skills development have been shown to have negative effects not only on relationships but also on educational performance (Tremblay, Hartup \& Archer, 2005), self-control (Tarullo, Obradovic \& Gunnar, 2009) and, later in life, on health (Felitti, Anda, Nordenberg, Spitz, Edwards, Koss \& Marks, 1998), employment status (Heckman, 2006), smoking, teen pregnancy, truancy and crime (Carneiro, Crawford \& Goodman, 2007). Children who are mistreated, neglected and/or abandoned by their parents, often don't feel worthy of love and this also affects their ability to form meaningful relationships with others.

Other children may be separated from their parents as a result of war, parental incarceration or death and court orders (social services), which results in their being placed in foster homes or group homes, even orphanages in some third world countries, often for extended periods (greater than 3 months). The anxiety and fear which grips these children (separation anxiety disorder) and the disruption of their attachment with a primary caregiver, has a profound effect on their social skills development and, subsequently, on their physical and emotional health and their futures. The scars from separation anxiety disorder where separation from 
Why Some Children Come to School with "Baggage"

primary caregivers is prolonged, often do not heal, particularly if the separation occurs within the formative years. There is evidence to suggest that this condition may lead to other disorders later in life - most notably panic disorder, agoraphobia, depression, dissociative disorders and posttraumatic stress disorder (Manicavasagar, Silove, Curtis \& Wagner, 2000).

Children affected by adverse experiences are said to go from distraction to dysfunction with predictable, inevitable consequences. Anti-social behaviour, aggression and poor school performance are just some of the outcomes. Adversity early in life profoundly affects the lives of these children even into adulthood (Bloom, 2000; Felitti et al 1998; Felitti, 2002; Weiss \& Wagner, 1998). Close to $80 \%$ of young adults in North America who have experienced abuse or neglect in childhood, are diagnosed with at least one psychiatric disorder (Silverman, Reinherz \& Giaconia, 1996) similar to those which result from separation anxiety.

Trauma is a disease of disconnection (Herman, 1997) and children who suffer from adverse childhood experiences are trauma survivors. This kind of trauma occurs within a social context and is not limited to personal suffering as a result of physical violence or separation, but also includes witnessing violence. Trauma can also result from the stigmatization associated with poverty, racism and sexual orientation (Covington, 2007).

Trauma survivors often feel unsafe in their own skin and their emotions and behaviours are frequently out of control as a result. According to Bloom (2000, p. 69), “...trauma always occurs in a social context and social wounds require social healing”. There is little doubt that schools can play a significant role in the healing process for these children (Wilkinson, 2014, in progress).

Traumatized children are frequently anxious, withdrawn, depressed and restless; some demonstrate hyper-arousal and detachment. In their attempts to be acknowledged in school, they 
Wilkinson

often act out in the classroom, interrupting the educational program and the learning of others which results in their becoming unpopular. They frequently demonstrate hostility toward other children and adults yet, ironically, also crave acceptance from their peers and the adults around them. These are children who are lacking in social skills and, as a result, they frequently find themselves excluded by other children. So desperate are these children to belong, that the more outgoing amongst them sometimes find ways to coerce other children into joining them by instilling fear (bullying). Sadly, they believe this is the only way to assemble a group of "friends" around them.

As long ago as 1945, psychologist William Goldfarb studied institutionalized children and those in foster care from the time they were placed in care. He proposed that the maternal deprivation suffered by these children not only produced a lag in their physical development but also in their psychological development and, as a result, the children demonstrated marked deficits in their ability to form interpersonal relationships.

In 1951, British psychologist and psychoanalyst James Bowlby worked with and studied what he later described as "affectionless" children (pp. 3-35, 38, 41). His central tenet was that children's experience of interpersonal relationships and consistency of loving care, are crucial to their healthy psychological development. He postulated that if infants and young children do not have continuous, warm, emotional relations with their primary caregivers (usually their mothers), there was likely to be irreversible negative consequences for both their normal healthy physical development and their mental health. Bowlby called for more detailed investigation of children's lives and proposed that the two most critical factors in a child's life for healthy development are a consistent, uninterrupted, emotional relationship with a nurturing primary caregiver and the quality of that caregiver's emotional attachment to the child. 
Why Some Children Come to School with "Baggage"

Even so, for decades afterwards, judges, doctors, attorneys and even family councillors and mediators made ill-advised decisions to remove children from their homes without thought to the profound trauma that results when children are separated from their primary caregivers (Haiman, 2014). Although these well-meaning decisions were in place to protect children from harm, the additional trauma and emotional scars that resulted from separation constituted attachment disruption with long-lasting negative repercussions well into adulthood (Bloom, 2000). Decisions made in family courts that affected the lives of young children, were not based on well-researched theories of psychosocial development such as attachment theory.

These days both legislative and judicial efforts have improved the courts' ability to respond to allegations of child neglect and/or abuse. Courts now have more alternatives and resources at their disposal (appendix A). Abuse, neglect, alcoholism, or other dysfunctional conditions that threaten the safety and wellbeing of a child are now necessary before the law will intervene with a court order to remove children from their homes in order to protect them. So compelling is the evidence of psychological harm and other detrimental effects caused by the separation of children from their biological families, that much more thought and more measured decisions are now made before such court orders are issued. Serious effort is made and alternate avenues explored in order to avoid placing children in foster care where possible, even if the subsequent care provided is less than optimal. According to Goldstein, Freud \& Solnit (1973), and Mnookin, (1973), placement in foster care should first reflect the emotional, social and physical needs of the child in question and always safeguard the need for consistency of care and continuity of positive family relationships.

Day to day, consistent, continuous, positive emotional and social interaction, companionship and shared experience are critical in retaining secure attachment (Lamb, 2003). A 
Wilkinson

strong attachment bond between child and primary caregiver (ideally the biological mother), includes the full range of shared emotional experience from extreme joy to extreme sadness, anger, fear etc. Interactive communication shapes both the structure and function of the developing brain (see: The Effects of Emotional Trauma, Attachment and Experience on the Developing Brain, p.21). Attachment experience has a direct effect on child development.

Secure attachment establishes the basis on which children will forge meaningful connections with others, their sense of trust, self-esteem and security in exploring their world, their capacity for self-control, ability to learn, emotional integrity and resilience to stress and for them to achieve optimal physical and mental health and social competence later in life (Coleman, 2003; Lieberman, Doyle \& Markiewicz, 1999). The reciprocal communication which develops between a mother and her infant also greatly facilitates the acquisition of speech (Bus \& van Ijzendoorn, 1988). Children who feel secure generally find greater acceptance from their peers and forge interpersonal connections easily (Kerns, Klepac \& Cole, 1996). They not only perform better in school as a result of their ability to focus and learn (Crittenden, 1992; Jacobson \& Hoffman, 1997) but also demonstrate appropriate social competence (Sroufe, Carlson \& Schulman, 1993). If secure attachment is established during the first four to five years of life, it can last a lifetime (Haiman, 2012).

The opposite is true of children with insecure attachment (Wong, Wiest \& Cusick, 2002). If bonding with primary caregivers is inconsistent or incomplete, emotional communication fails and insecure attachment arises. Insecure attachment is the result of failed communication and disconnection which negatively influences right brain development. Lack of connectivity and social-emotional competence, as well as trauma due to neglect, abuse and/or separation may 
Why Some Children Come to School with "Baggage"

negatively affect a child's development, academic performance, and overall health and behaviour (Blum \& Libbey, 2004).

Children whose attachment is insecure, particularly during the formative years, have problems with anxiety, self-regulation and control (impulsivity), inappropriate over-reaction to stimuli, low tolerance for stress and frustration and are at greater risk for depression, aggression, violence, substance-abuse and suicide. Those placed in foster care endure the added stresses of attachment disruption (see: Trauma Due to Separation From Primary Caregiver and Substitute Care [Attachment Disruption] p.14), which leads to difficulties forming positive relationships with others. Their capacity for empathy may also be impeded. This inability to feel for others can be passed on to future generations (Miller, 1990).

Surprisingly, some parents are unaware of the importance of maternal love and nurturing touch for infants and children. Similarly they are sometimes ignorant of the problems that can result during childhood and adolescence if an infant does not form early attachment with its primary caregiver. Absent, inactive and distracted parents, insensitive to their infant's needs and communications, usually set the wheels of regression in motion. Most parents of insecure children are, themselves, products of insecure relationships. Unless timely and appropriate repair occurs, this failed attachment is passed on from one generation to the next (Bowlby, 1973).

Not so well-known and, as yet, largely under-examined (Luthar, 2003), are the problems facing some children at the upper end of the socioeconomic spectrum - children presumed to be at low risk who, generally, have not suffered trauma but who have similar difficulties with certain social skills. What they have in common with children who have been traumatized, are their frequent feelings of disconnection, isolation from parents and difficulty forming meaningful, appropriate connections with others. These children report higher levels of anxiety and depression than most other children and, as a result, the incidence of substance abuse 
Wilkinson

(alcohol and illicit drugs) and self-medication has been found to be more frequent amongst them (Luthar \& D’Avanzo, 1999). In these cases, they may have parents who are preoccupied with high-powered jobs, who travel extensively and who are therefore frequently unavailable to their children. Many wealthy parents lavish their offspring with material excess as a substitute for time spent together. Their children are often rebellious and eager to disconnect themselves from social norms (Barnham, 2004). Despite their elevated social standing, privileged children are also not immune from abuse.

Psychologist and science journalist, Daniel Goleman, in his book “Social Intelligence: The New Science of Human Relationships" (2006), makes reference to the work of psychologist Jerome Kagan whose most notable research is in the field of the development of human moral sense and the human temperament. According to Kagan (2006), in addition to their biological bias for negative emotions such as aggression, selfishness and anger, human beings also have a strong bias for positive emotions like love, nurture, kindness, compassion and cooperation. Fortunately, due to the plasticity of the human brain, we can be taught to unlearn negative emotions and develop positive ones. There is little doubt that schools can play a significant role actively modelling and teaching positive emotions and in the healing process for children at risk (Wilkinson, 2014).

\section{Social Skills Impairment: Common Causative Factors}

\section{Trauma due to Poverty}

Empathetic and caring parents in secure relationships, nurture their children and form strong attachments with them. They provide sensory input, intimacy and appropriate touch as a necessary part of their nurturing. They model, sometimes unknowingly but naturally, a plethora 
Why Some Children Come to School with "Baggage"

of social and emotional skills such as empathy, compassion, tolerance, patience, gratitude, respect, cultural sensitivity, self-control and responsibility.

Some parents living under the stressful conditions of poverty and, perhaps, addictions and family violence, may be overwhelmed by the hopelessness of their situation and, as a result, they don't see, or choose to ignore, their children's need for emotional closeness. Frequently, these parents have, themselves, been victims of neglect and abuse. Some may have been separated from their parents when they were young, for example those who were victims of residential schools. They have had little or no experience with empathy, nurture or compassion, and are therefore unable to model, for their children, the social skills necessary for the formation of healthy relationships with others. They tend not to form strong, secure family relationships or attachment with their children due to their adverse circumstances. This has a profound effect on social skills which are found to be deficient in at risk children (Heckman, 2008; Moroz, 2005).

Unhealthy attachment (due to substance abuse and/or family violence) or lack of attachment to parents as a result of parental absence (due to incarceration or separation), interferes with a child's ability to connect with others and form healthy, meaningful relationships. Like their parents, it is difficult for children who have not experienced compassion, to demonstrate it for others. Similarly, it is close to impossible for children who have been raised in non-empathic relationships to develop empathy which, according to author and educator Michele Borba (2001), is first on a list of "Seven essential virtues of moral intelligence" (pp. 68), and, interestingly, it is a sentiment notably absent in children who bully.

It must be said that not all children who grow up in poverty have poor social skills. Those with loving parents who rise above their conditions of poverty to hold their families and moral values together, usually raise resilient, respectful and intelligent children with an abundance of 
Wilkinson

social skills. Generally speaking, those who have been loved, love; those who have been listened to, listen; those who have been cared for, care.

For other parents, however, the dismal prospect of joblessness and poverty often reduces them to feelings of hopelessness. For these unfortunate people, substance abuse provides a way to cope with and/or detach themselves from their situations and often results in family violence. These are the factors which have a traumatic effect, both physiologically and psychologically, on their children. Children who witness family violence and aggression, often become aggressive; those who have been hurt, often hurt others.

\section{Trauma due to Separation from Primary Caregiver, Court Order and Substitute Care (Attachment Disruption)}

Separation of children from their primary caregiver(s) has a serious damaging effect on normal development (Lawrence, Carlson \& Egeland, 2006), social skills, the ability to forge meaningful relationships, learning and overall health (Bowlby, 1951; Goldfarb, 1943; Levy, 1937). It used to be that when children were removed from their parents by the state, as a safety measure in times of war, in the event of parental death, dire home conditions (violence, addiction, abuse etc.) or because the children, themselves, had significant mental health issues or serious behaviour problems, they were sent to orphanages. There are now very few orphanages in the developed world and many of these are being phased out in favour of foster care and adoption services. A large number of orphanages may still be found in underdeveloped countries, and for children in these countries who are not likely to be adopted, the orphanage has become a tragic necessity. However, these days, most are run by church organizations and conditions, for the most part, have been greatly improved. 
Why Some Children Come to School with "Baggage"

For more than 100 years, aboriginal children in Canada were taken away from their parents and sent to residential schools built and run by the Government of Canada and the Catholic, Anglican, Methodist, United and Presbyterian churches. It was considered appropriate to attempt to make aboriginal children blend in with non-aboriginals, to learn to think like them, dress like them and speak only English or French. To ensure success in this endeavour, children were often taken into schools long distances away from their parents and communities and kept in residence for many years, separated from their families and their culture. Their experiences were much the same as those of children living in orphanages. Many residential schools were overcrowded and dirty. Children were often not given enough food and clothing. Those who didn't die of disease and malnutrition emerged damaged and changed.

It is no accident that $40 \%$ of aboriginal prison inmates in Canada today, were victims of separation, neglect and abuse in residential schools. Aside from the effects of their horrific living conditions as a result of this shameful tragedy, removal from their parents at a young age will have had a profound and traumatic effect on them both physiologically and psychologically and, no doubt, led them to criminal activity. These adverse effects would, in turn, come to be inherited by their children.

These days, children who are removed from their home environment, for whatever reason, are usually sent to group homes as a temporary measure until foster parents can be found for them. Foster care, a protective intervention, is ideally, also a temporary measure until children can either be returned to their original homes (if conditions improve) or put up for adoption in stable home environments. Young children are more likely than older children to be placed in foster care. In a review of foster care in 2000, the incidence of children under five years old placed in foster homes was double that of children aged 5 to 17 (Goerge \& Wulczyn, 1998). 
Wilkinson

A large number of children living in foster care, are already "damaged" by their preexisting living conditions (parents suffering from alcoholism, drug abuse poverty, poor nutrition and family violence etc.) or by the loss of parents in wars or world disasters. Their adoptability varies considerably with factors like age, race, gender, physical and academic ability, mental health and behavioural considerations. It is a cruel fact that many damaged children, through no fault of their own, may never be adopted and will, probably, remain in the system for extended periods.

Many foster children are bounced around between group homes and foster parents. Multiple placements and long-term, inconsistent foster care, results in impaired social functioning and emotional problems related to attachment disruption. Young children may eventually become attached to foster caregivers if they are nurtured and their needs are met, but frequent changes in caregivers disrupt this attachment. If attachment is interrupted (by separation of the child from the primary caregiver), or is inconsistent (placement in group home or moved from one foster home to another), communication fails, insecurity sets in and children regress in all areas (affections, skills, achievements, and social and emotional interaction).

Substitute care is typically associated with attachment disruption (Troutman et al., 2000). The more changes in caregivers young children experience, the more likely they are to exhibit oppositional behaviour, constant crying and inappropriate clinging (Gean, Gillmore \& Dowler, 1985). Very young children who have experienced disrupted attachment also have a propensity for reactive attachment disorder in which the child presents with severe disturbances in relationships with caregivers and others. The longer a child is left in the system, the more immutable are the detrimental emotional, physical and psychological effects. There is also a stigma associated with being a foster child and foster children sometimes feel devalued by 
Why Some Children Come to School with "Baggage"

society due to low expectations from their foster parents and teachers and misconceptions about a relationship between foster children and delinquency (Lamb, 1981).

Despite their dismal, abusive and often dangerous living conditions, most children who have suffered adverse childhood experiences still feel unconditional love for the very parents that neglect and abuse them (Bowlby, 1951). As a result, separation from these parents by intervening authorities, can be problematic for children and placement in foster care often results in feelings of fear, isolation, anxiety and mistrust.

It is true that, despite rigorous screening, some foster care households abuse the system and only take in foster children for financial gain and government benefits. In these cases, the living conditions and relationships may be no better than they were in the children's former homes. More frequently, since requirements for foster care workers have been tightened (they must now be licensed, certified and approved), most foster homes today provide a safe and secure environment with compassionate adults to care for their, often challenging, foster children. Where possible, siblings are kept together so that children do not feel totally isolated from their biological families. Foster children who, due to dire home circumstances, lose all contact with their biological families, usually receive psychological treatment to help them cope with separation.

While most of the psychological and emotional damage to children, described by erudite researchers in the field (Bowlby, 1951, 1988; Curtis, Dale, Kendall \& Rockefeller, 1999; Fisher, Gunnar, Dozier, Bruce \& Pears, 2006; Haiman, 2014; Mnookin, 1973; Rutter, 2000), is attributed to separation as a result of foster care, we cannot forget that most of the children placed in care were recommended for foster care because they were already damaged. The symptoms of neglect, abuse, and trauma as a result of violence in the home, (fear, feelings of 
Wilkinson

loss, anxiety, depression, restlessness, poor social skills, lack of self-control, low self-esteem, heightened aggression, attention deficits, inability to form meaningful relationships), bear a striking resemblance to the symptoms described as the result of attachment disruption due to a change in primary caregiver. Clearly, children and adolescents who are taken from their parents, their siblings and their homes, suffer a double dose of trauma when they are placed in foster care and/or offered up for adoption. The cluster of adverse conditions renders these children even more vulnerable to develop emotional and behavioural problems (Lawrence et al, 2006).

It would appear from the research that very young children less than 1 year old, in the absence of neglect and/or abuse, placed in institutions or foster care in the 1930s, where there was no stimulation, nurture, love and little human contact, suffered major retardation both in growth and mental/emotional development (Robertson, 1958). This was believed to be due to separation anxiety disorder which can lead to a variety of attachment disorders as time goes on. Those same children, placed in government regulated foster care today, would be expected to do well. Since, at less than one year old, they may not have had sufficient time to fully bond with their biological mothers and memory would be short, separation anxiety or attachment disruption would likely not be issues.

Beyond one year however, again in the absence of neglect and/or abuse, children have usually bonded with their primary caregivers and developed emotional memory. For these children, despite the quality of their foster care, adjustment to a different (or many) caregiver(s) is usually problematic and attachment disruption is common (Troutman et al., 2000). Again, lack of consistency with caregivers undermines a child's attempt to form secure attachment with others. 
Why Some Children Come to School with "Baggage"

To ascertain the true effects of separation, one might look to the research conducted by Bowlby(1951), Goldfarb (1943, 1945), Levy (1937), Robertson (1952, 1958), Skeels (1966) and Spitz $(1945,1946,1952)$. These researchers looked at the effects of separation on children who had not been traumatized by abandonment, neglect and/or abuse, but who had been either placed in institutions and/or foster care soon after birth (given up by their birth mothers) or placed in hospitals for prolonged periods (more than 3-5 months) at a time in history when it was believed to be "better for the child" if parents were not allowed to visit (appendix B).

\section{Disconnection due to Emotionally Unavailable Parents}

We have looked at the effects of poverty and neglect on children and the unhealthy attachment that results between children and parents who may be abusive, absent due to incarceration, substance abuse or who, themselves have experienced adverse childhood experiences. Feelings of disconnection also exist in some children from the opposite end of the socio-economic spectrum. Some children from privileged environments feel disconnected from parents due to overscheduling and material excess as a substitute for time spent together as a family (power parenting).

Privileged children are not usually considered to be "at risk". Social skills impairment does not, at first glance, seem to be as apparent in children from wealthy families. Many of them are well-mannered and polite but may also be selfish and self-absorbed. They frequently have problems with empathy and tolerance and for this reason, like many children living in poverty, they feel disconnected and have difficulties forging friendships. More scientific research needs to be conducted to examine the physiological and psychological costs of growing up in affluence. These children are also not immune to abuse or touch deprivation and disconnection from 
Wilkinson

parents. All children need parents who are not only physically but also emotionally available to them. Many wealthy parents are unavailable to their children due to preoccupation with highpower professions, fatigue and heavy work and travel commitments.

Author and clinician Michael Unger (2009), writes about wealthy families' living in large, sterile homes designed to provide all family members with their own space, their own televisions and electronic gadgetry (pp. 157-185). The opportunities for families to spend time in close proximity are limited as a result. Some wealthy people choose to live in gated communities on large lots where contact with neighbours and neighbourhood children is also limited. The opportunities for their children to form meaningful relationships with parents and others are few and far between.

Privileged children often have divided disciplines since their main caregivers are, frequently, not related to them but are employees of their parents. Wealthy parents are often on a guilt trip and compensate their children's need for their presence and attention by enrolling them in a wide variety of extra-curricular activities (Rosenfeld \& Wise, 2000), often under the supervision of non-family members. They also frequently lavish their children with expensive toys, electronic babysitters, and, since many of these parents tend to be overly permissive (Unger, 2009, p.109), they impose few boundaries. Their children often feel insecure, lack purpose and suffer from material excess. These parents, though well-meaning, believe they can purchase their children's love and success and attempt to design their children's lives rather than watch and wait for them to unfold (another example of power parenting).

This over-indulgence usually results in children who are tired, over-anxious, apathetic and self-centred with an inflated sense of entitlement, a strong desire for fame and skewed values. Despite their tiredness, often as a result of insomnia, they are often highly competitive, 
Why Some Children Come to School with "Baggage"

have no idea how to share, how to take turns, or how to feel empathy and compassion for others. Their "little prince" and "princess" attitudes make them unpopular with other children. Their resulting general unhappiness often leads these children to rebel against social norms. They sometimes forge inappropriate relationships, hang out in gangs, become involved in cyberbullying (Kaukiainen, Bjorkqvust, Lagersptez, Ostrman, Salmivalli, Rothberg, \& Ahlbom, 1999) and, as they grow older, turn to substance and alcohol abuse to alleviate distress (Luthar \& D’Avanzo, 1999; Smith, 2002) all of which can lead to trouble with the law. Professional parents also frequently put undue pressure on their children to achieve. This kind of power parenting can lead to depression and anxiety in their children.

\section{The Effects of Emotional Trauma, Attachment and Experience on the Developing Brain}

We are born with approximately 100 billion neurons. More important than the number of neurons are the connections they make (synaptic connections). By adulthood, these neurons branch out to each other to form around 100 trillion connections. This increase is due almost solely to the effects of experience. Experience not only creates connections, it also prunes them (Weiss, 1998). There are numerous studies which document the unequivocal effect of early experience on brain development.

Interactive communication shapes both the structure and function of the developing brain. During the first years of life, attachment, the bonding between infant and primary caregiver, progresses. The quality of this attachment affects right brain growth (Haiman, 2014). The right hemisphere of the brain is responsible for processing related to our social interactions and emotions. Most right brain development occurs within the first 2-3 years of life. These years are critical for the formation of secure attachment between infant and caregiver (usually the mother). 
Wilkinson

Studies have shown that the manifestations of right brain growth and development that occur in this critical period can last a lifetime (Schore, 2002).

According to Daniel Goleman (2006), human beings are hard wired for cooperation, collaboration and teamwork. These are the keys to our future happiness, effectiveness and prosperity. Goleman points to new scientific studies including social neuro-science which measures the neural dynamics of human interactions. He discusses the infectious nature of human emotions - how they are transmitted from one person to another, actually altering neural circuits in the brain. Scientists have observed how brains "light up" in response to certain social interactions and how people are affected, positively or negatively, by the actions of others (what others say and do, their demeanour and mood etc.).

Trauma due to poverty, attachment disruption and disconnection, interferes with normal healthy brain development and is the overriding cause of social skills impairment in children. Insecure attachments between parents and children influence the developing brain which, in turn, affects children's ability to forge meaningful connection with others, their self-esteem and selfcontrol, their ability to learn and to enjoy optimal physical and mental health (Wilkinson, 2014). A period of maternal deprivation, trauma due to neglect and/or abuse, particularly in the formative years, also leads to changes in the brain that may persist into adulthood.

Trauma releases the "fight or flight" hormones, cortisol \& adrenaline, into the system to prepare an individual for a stressful situation. While these steroids are essential to prepare us for impending danger, they are also toxic when they are "turned on" for too long; they become so focussed on the situation at hand that they shut down executive function thinking (Teicher, 2000). 
Why Some Children Come to School with "Baggage"

Constant repetition of this kind of trauma affects normal brain development (Perry, Pollard, Blakley, Baker \& Vigilante, 1995) and children who are exposed to it have a hard time with self-control (sitting still, impulsivity) and frequently have learning, attention, social and behaviour problems. In addition to adverse extrinsic factors, many of these children have suffered pre-natal stressors where there has been maternal substance abuse (e.g. alcohol abuse in expectant mothers can lead to foetal alcohol syndrome).

The brain is at its most malleable in the first few years of life. It is during this sensitive period that much of the damage caused by negative experiences is reversible if timely and appropriate intervention is implemented. Since different systems in children's brains develop at different times (brain systems develop sequentially from the brainstem to the cerebral cortex), there are definite critical periods for the healthy development of various brain functions. The healthy development of complex systems in the cerebral cortex (social emotional skills such as impulse control, regulation of anxiety, mood, moral reasoning, abstract thought etc.), depends greatly on the healthy development of less complex systems in the brain stem and mid-brain. Anything that interferes with the healthy development of the brain stem and mid brain (trauma), will significantly affect the healthy development of these more complex systems in the cortex.

The first three years of life are critical for the development of the cerebral cortex. Experience can change the mature brain but experience during the critical periods of early childhood development, organizes brain systems. Trauma during infancy and early childhood has the potential to influence the permanent organization of all functional capabilities in young children (Perry et al., 1995).

The early childhood environment helps to shape self-control pathways in the developing brain. Self-control is another skill that children need to succeed academically, socially, and 
Wilkinson

emotionally. Brain regions essential to self-control are immature at birth and develop slowly throughout childhood. From ages 3 to 6 years, as these brain regions become more mature, healthy, nurtured children show improved ability to control impulses, shift their attention flexibly, and await reward.

\section{Discussion}

Meaningful connections are at the heart of appropriate social skills development. All children crave connections with others, but if the building blocks (empathy, compassion, selfcontrol, tolerance and concern for others) for making such connections are not in place, some children may quickly find themselves isolated, excluded, separated from the crowd, due to their poor social skills and inability to make friends.

We have looked at the effects of trauma due to poverty, separation and disconnection and the resulting attachment disruption in children from different backgrounds. What all these children have in common is impairment in social emotional skills development and the ensuing inability to form meaningful connections with others.

Meaningful, social-emotional relationships are critical to normal brain development, optimal health and wellbeing, learning and performance. All children benefit enormously from developing their social skills but most particularly children who have suffered adverse childhood experiences. Social-emotional strengths grow in tandem with knowledge and skill. As students develop these skills, they grow more confident, and with this confidence comes greater engagement, self-control, competence, sociability and enhanced self-esteem. These are the skills that enable children to forge meaningful connections with others and to get along with those around them. 
Why Some Children Come to School with "Baggage"

Children living under the stigma and conditions of poverty, as well as those who have been separated from, or deprived of, a close attachment with parents, have been shown to be deficient in social skills (Heckman, 2008; Moroz, 2005). These are the children who often come to school with "baggage". Social skills such as empathy, patience, tolerance and self-regulation are crucial not just for the formation of meaningful relationships with others but for a healthy and successful transition into adulthood.

If social emotional skills are not taught and modelled at home, it behoves schools to take on the responsibility, as part of a healing process for traumatized children, to model and actively teach appropriate social-emotional skills alongside cognitive skills. Wider awareness of the importance of deliberately emphasizing social-emotional skills in both teaching and learning is key (Carneiro, Crawford \& Goodman, 2007; Comer, 1988; Wilkinson, 2014). Deliberate school interventions can positively influence non-cognitive (social-emotional) outcomes (Levin, 2012). Addressing deficits in this area of learning benefits everyone and school environments in particular, become more positive as a result (Wilkinson, 2014).

Most children who are lacking in social skills are not simply "bad kids". Through no fault of their own, they are frequently victims of trauma and/or disconnection. It is crucial that teachers understand why some children come to school with so much "baggage". Once educators know and understand what is going on in the lives and brains of these children, schools may become more active participants on their journey toward healing. In order to embark on this journey, those who design educational programming and staff training will put their understanding to good use. Schools will discover better ways to accommodate the special needs of damaged children and translate current research into school policy to the benefit of everyone involved. 


\section{Wilkinson}

Student populations are mutable. Schools need to constantly recreate themselves in order to accommodate the myriad needs of children, particularly those who come to school from traumatic environments (Wilkinson, 2014), in order to secure a peaceful and optimal learning environment for all. 
Why Some Children Come to School with "Baggage"

\section{Appendices}

\section{Appendix A: Child Protection in Canada}

The benefits of protection for children vs the potential penalties for abusive parents are now carefully measured. If a child is deemed to be in danger, a civil protection petition may be filed. Those intervening in cases of alleged neglect and/or abuse are trained to be sensitive to the cultural norms of the family involved since there is often a wide range of ethnic, social and economic differences which exist in families where child maltreatment occurs. Since research has demonstrated the negative effects of child-parent separation, child welfare agencies make reasonable efforts to keep the family unit intact where possible or to reunite a family where the child has already been removed for reasons of safety.

The Children's Aid Society (C.A.S.) in Canada intervenes when any child under the age of 16 is threatened by physical or emotional harm, sexual abuse and/or neglect. When a report is made, a C.A.S. worker visits the home of the child in question to assess the situation. If a child appears to be at risk, the family may be offered support services. If it is clear that the family is unable to provide adequate support and a child appears to be in immediate danger, the child may be temporarily removed from the home, with or without parental consent. Children who are removed from their homes by C.A.S. are taken to safe environments - preferably to the homes of family relatives or friends. If relatives or friends are unable to help, these children are placed in foster care approved by C.A.S. If parents object to their child's removal from home, a family court judge may issue a court order to place the child under the care of C.A.S. However, children's rights and wishes, wherever possible, are respected in a way that is appropriate to their age and level of understanding and parental visits are allowed at the discretion of the family court judge. 
Wilkinson

\section{Appendix B: Separation Due to Prolonged Hospitalization}

In the early 1940s, many psychologists, psychiatrists and pediatricians were growing increasingly concerned about high child mortality rates in hospitals where family visitors were banned for a number of reasons, most notably because of the risk of spreading infection. Parents of children who were hospitalized for any length of time, were denied access to their children and prohibited from visiting more than once a month. Some hospitals did not allow visiting at all if children were 3 years old or younger. Reasons given for restricted visits included not only the potential for the spread of infection, but also the risk of disturbed hospital routines and the concern that children, especially those expected to be hospitalized for any length of time, would not "settle".

Most children were frightened and upset going into hospital and cried inconsolably when their parents first left them and at the end of their infrequent visits. This was simply regarded as the inevitable consequences of being hospitalized. No thought was ever given to attachment disruption and the profound emotional and psychological damage this might cause. Nurses were concerned with feeding, bathing and administering medicines. They were actively discouraged from forming attachments with the children in their care and were often disciplined if they approached patients other than to attend to these basic needs.

The children were later shown to suffer from the myriad symptoms of separation anxiety disorder (Hendrick, 1994). The scars from this disorder run deep and there is evidence it may lead to other later-developing disorders most notably attachment and panic disorders, agoraphobia, depression and post-traumatic stress disorder (Manicavasagar et al., 2000).

Several researchers (Bowlby, 1951; Robertson, 1952 \& 1958; Spitz, 1945 \& 1952) tried to make the authorities see that there was serious risk of developmental and psychological damage 
Why Some Children Come to School with "Baggage"

for these children, including their ability to forge stable, cooperative relationships with others, but their warnings fell on deaf ears. The world, at this time, was preoccupied with a second world war and, despite overwhelming evidence that hospitalized children were suffering as a result of separation from their parents, reform did not come until much later.

John Bowlby, commissioned by W.H.O. to prepare the monograph "Maternal Care and Mental Health" (1951), made many recommendations for the reform of hospital policies around parental visits but his work was controversial and the authorities did not, at first, take notice. In 1952, psychiatric social worker and psychoanalyst, James Robertson, collaborated with Bowlby and together they brought this shameful situation to light with their influential film "A Two Year Old Goes to Hospital". Robertson's work had a significant effect on the medical profession and was used as evidence presented before the government appointed Committee on the Welfare of Children in Hospital (1959). The report of the Committee was based on evidence submitted by Lightwood, Craig, Harvey, McCarthy, MacKeith, Pickney \&Tizard who made fifty-five recommendations including the reformation of hospital visiting. The welfare of children in hospital had been largely ignored by the government up until this time.

In 1952, Austrian-American psychoanalyst Rene Spitz also produced a film in the United States to demonstrate what he called psychogenic disease in infants. This disturbing film shows the psychological and physiological deterioration of infants who had been hospitalized for extended periods with little or no access to their primary caregivers.

Widespread changes to the care of institutionalized and hospitalized children were also outlined in the W.H.O.'s publication “Deprivation of Maternal Care: a reassessment of its effects" (Ainsworth, Andry, Harlow, Lebovici, Mead, Prugh \& Wooton, 1962). In addition to 


\section{Wilkinson}

changes in the care of institutionalized children, the practice of allowing more frequent and extended parental visits to children in hospital became the norm. Thanks to these researchers and others for alerting the authorities to the devastating effects of parent-child separation. These days parents are permitted to "live in" with very young children who are hospitalized and there are no restrictions on visiting for parents and other family members for children of any age.

Dedication: This paper is dedicated to the memory of a talented and courageous sister, Carole Gregory (1942-1983) who, following prolonged hospitalization as an infant, struggled with the after-effects of separation anxiety disorder for most of her unfinished life. 
Why Some Children Come to School with "Baggage"

\section{References}

Ainsworth, M.D., Andry, R.G., Harlow, R.G., Lebovici, S., Mead, M., Prugh, D.G., \& Wooton. B. (Contributors) (1962). Deprivation of maternal care: a reassessment of its effects. (Public health papers; no. 14). World Health Organization: Geneva.

Anda, R.F., Felitti, V.J., Bremner, J.D., Walker, J.D., Whitfield, C., Perry, B.D., Dube, S.R., Giles, W.H. (2006). The enduring effects of abuse and related adverse experiences in childhood. European Archives of Psychiatry and Clinical Neuroscience,_256 (3), 174186.

Barnham, N. (2004). Disconnected. London: Random House.

Benson, P.L., Sharma, A.R., \& Roehlkepartain, E.C. (1994). Growing up adopted: A portrait of adolescents and their families. Minneapolis, MN: Search Institute.

Bloom, S. (2000). Creating Sanctuary: Healing from systematic abuses of power. Therapeutic Communities, 21 (2), 67-91

Blum, R.W, \& Libbey, H.P. (2004). Wingspread declaration on school connections, Journal of School Health, 74 (7), 233-234.

Borba, M. (2001). Building Moral Intelligence:The Seven Essential Virtues That Teach Kids to Do the Right Thing. San Francisco, CA: Jossey-Bass.

Bowlby, J. (1951). Maternal Care and Mental Health. World Health Organization: Geneva.

Bowlby, J. (1973). Separation, Anxiety and Anger. New York: Basic Books.

Bowlby, J. (1988). A Secure Base: Parent-Child Attachment and Healthy Human Development. Tavistock Professional Book. London: Routledge.

Bus, A.G. \& van Ijzendoorn, M.H. (1988). Mother-child interactions, attachment, and emergent literacy: A cross-sectional study. Child Development, 59, 1262-1272.

Carneiro, P., Crawford, C. \& Goodman, A. (2007). The Early Impact of Cognitive and NonCognitive Skills on Later Outcomes. London: Centre for the Economics of Education.

Coleman, P.K. (2003). Perceptions of parent-child attachment, social self-efficacy, and peer relationships in middle childhood. Infant and Child Development, 12, 351-368.

Comer, P.J. (1988). Educating poor minority children. Scientific American, 259 (5), 42-48.

Covington, S. (2007). The Relational Theory of Women's Psychological Development: Implications for the Criminal Justice System. In Ruth T. Zaplin (Ed.), Female Offenders: Critical Perspectives and Effective Intervention, (1-20). Burlington, MA: Jones \& Bartlett. 
Wilkinson

Crittenden, P.M. (1992). Treatment of anxious attachment in infancy and early childhood. Development and Psychopathology, 33(4), 575-602.

Curtis, P.A., Dale, G. Jr., Kendall, J.C., \& Rockefeller, J.D. (1999). The Foster Care Crisis: Translating research into policy and practice. Lincoln, NE: University of Nebraska Press.

Felitti, V.J. (2002). The Relationship of Adverse Childhood Experiences to Adult Health: Turning gold into lead. Psychosomatic Medicine \& Psychotherapy, 48 (4), 359-369.

Felitti, V.J., Anda, R.F, Nordenberg, D., Williamson, D.F., Spitz, A.M., Edwards, V., Koss, M.P., Marks, J.S. (1998). The relationship of adult health status to childhood abuse and household dysfunction. American Journal of Preventive Medicine, 14, 245-258.

Fisher, P.A., Gunnar, M.R., Dozier, M., Bruce, J. \& Pears, K.C. (2006). Resilience in Children. Annals of the New York Academy of Sciences, 1094, 215-325.

Gean, M., Gillmore, J. \& Dowler, J. (1985). Infants and toddlers in supervised custody: A pilot study for visitation. Journal of the American Academy of Child Psychiatry, 24 (5), 608612.

Goerge, R. \& Wulczyn, F. (1998). Placement experiences of the youngest foster care population: Findings from the multistate foster care data archive. Zero to Three, 19 (3), 17-21.

Goldfarb, W. (1943). Infant Rearing and Problem Behavior. American Journal of Orthopsychiatry 13 (2), 249-265.

Goldfarb, W. (1945). Effects of Psychological Deprivation in Infancy and Subsequent Stimulation. American Journal of Psychiatry, 102, 18-33.

Goldstein, J., Freud, A. \& Solnit, A.J. (1973). Beyond the Best Interests of the Child. New York: The Free Press.

Goleman, D. (2006). Social Intelligence: The New Science of Human Relationships. New York: Bantam Books.

Haiman, P.E. (2012, July). Effects of Early Attachment on Childhood and Beyond. The Attached Family, (Online extension of Attachment Parenting International's Attached Family magazine). Retrieved, June 2014, from http://www.peterhaiman.com/articles/effects-ofearly-attachment-on-childhood-and-beyond.shtml

Haiman, P.E. (2014). Effects of Separation on Young Children: Implications for family court decision making. Parent-Child Relationships. Retrieved, April 2014, from www.peterhaiman.com/child-rearing-solutions

Heckman, J. J. (2006). Skill Formation and the Economics of Investing in Disadvantaged Children. Science, 312 (5782), 1900-1902. 
Why Some Children Come to School with "Baggage"

Heckman, J.J. (2008). Schools, Skills and Synapses. Economic Enquiry, 46 (3), 289-324.

Hendrick, H. (1994). Child Welfare: England 1872-1989. New York: Routledge.

Herman, J.L. (1997). Trauma and Recovery. New York: Basic Books.

Kagan, J. (2006). In Anne Harrington \& Arthur Zajonc (Eds.), The Dalai Lama at MIT. Cambridge, MA: Harvard University Press.

Kaukiainen, A., Bjorkqvust, K., Lagersptez, K., Osterman, K., Salmivalli, C., Rothberg, S. \& Ahlbom, A. (1999). The relationships between social intelligence, empathy, and three types of aggression. Aggressive Behavior, 25, 81-89.

Kerns, K., Keplac, L \& Cole, A. (1996). Peer relationships and pre-adolescents' perceptions of security in the child-mother relationship. Developmental Psychology, 32 (3), 457-466.

Lamb, M.E. (1981). The Development of Social Expectations in the First year of Life. In Lamb, M.E. \& Sherod, L.R. (Eds.), Infant Social Cognition: Empirical and theoretical considerations (155-175). Hillsdale, NJ: Erlbaum.

Lamb, M. (2003). Child Development and the Law. Handbook of Psychology, (6), 559-577. Mississauga, Ontario: Wiley.

Lawrence, C.R., Carlson, E. A. \& Egeland, B. (2006). The Impact of Foster Care on Development. Development \& Psychology, 18, 57-76.

Levin, H.M. (2012). More Than Just Test Scores, Prospects: Quarterly Review of Comparative Education. Retrieved, March 2013, from $w$ ww.roundtheinkwell.files.wordpress.com

Levy, D. (1937). Primary Affect Hunger. American Journal of Psychology, 94, 643-652.

Lieberman, M., Doyle, A.B. \& Markiewicz, D. (1999). Developmental patterns in security of attachment to mother and father in late childhood and early adolescence: Associations with peer relations. Child Development, 70, 202-213.

Lightwood, R., Craig, W.J., Harvey, C.C., McCarthy, D., MacKeith, R., Pickney, C. \& Tizard, J.P.M. (1959). The Welfare of Children in Hospital. British Medical Journal, 1 (5115), 166-169.

Luthar, S.S. \& D’Avanzo, K. (1999). Contextual Factors in Substance Abuse: A study of suburban and inner-city adolescents. Development and Psychopathology, 11, 845-867.

Luthar, S. S. (2003). The Culture of Affluence: Psychological Costs of Material Wealth. Child Development, 74 (6), 1581-1593.

Manicavasagar, V., Silove, D., Curtis, J. \& Wagner, R. (2000). Continuities of Separation Anxiety From Early Life Into Adulthood. Journal of Anxiety Disorders, 14 (1), 1-18. 
Wilkinson

Miller, A. (1990). For Your Own Good: Hidden cruelty in child-rearing and the roots of violence. $\left(3^{\text {rd }}\right.$ ed.) New York: Farrar, Straus \& Giroux.

Mnookin, R. (1973). Foster Care: In Whose Best Interest? Harvard Educational Review, 43, 599-638.

Moroz, K.J. (2005). The Effects of Psychological Trauma on Children and Adolescents. Report Prepared for the Vermont Agency of Human Services, Department of Health, Division of Mental Health, Child, Adolescent and Family Unit.

Perry, B.D., Pollard, R.A., Blakley, T.L., Baker, W.L. \& Vigilante, D. (1995). Childhood Trauma, the Neurobiology of Adaptation, and 'Use-dependent' Development of the Brain: How 'States' become 'Traits'. Infant Mental Health Journal, 16 (4), 271-291.

Robertson, J. \& Bowlby, J. (1952). A Two-year-old Goes to Hospital. Film/Video file. Retrieved, April 2104, from www.youtube.com/watch?v=RqX2N_T2bGk

Robertson, J. (1958). Young Children in Hospital. London: Tavistock Publications.

Rosenfeld, A. \& Wise, N. (2000). The Overscheduled Child: Avoiding the hyperparenting trap. New York: St. Martin's Griffin.

Rutter, M. (2000). Children in Substitute Care: Some conceptual considerations and research implications. Children and Youth Services Review, 22, 685-703.

Schore, A. (2002). Dysregulation of the Right Brain: A fundamental mechanism of traumatic attachment and the psychogenesis of post-traumatic stress disorder. Australian \& New Zealand Journal of Psychiatry, 36, 9-30.

Silverman, A.B., Reinherz, H.Z., \& Giaconia, R.M. (1996). The long-term sequelae of child and adolescent abuse: a longitudinal community study. Child Abuse and Neglect, 20 (8), 709-723.

Skeels, H. (1966). Adult Status of Children with Contrasting Early Life Experiences. Monographs of the Society for Research in Child Development, 33, 1-65.

Smith, M. (2002, November 17). Are kids from affluent families more likely to drink? Mobile Register, Alabama.

Spitz, R.A. (1945). Hospitalism-An Inquiry Into the Genesis of Psychiatric Conditions in Early Childhood. Psychoanalytic Study of the Child, 1, 53-74.

Spitz, R.A. (1946). Hospitalism; a follow-up report on investigation described in Volume I, 1945. Psychoanalytic Study of the Child, 2, 113-117.

Spitz, R. A. (1952). Psychogenic Disease in Infancy. (A film produced by the Psychoanalytic Research Project on Problems of Infancy: Emotional Deficiency Disease.) Retrieved, May 2014, from www.youtube.com/watch?v=VvdOe10vrs4 
Why Some Children Come to School with "Baggage"

Sroufe, L.A., Carlson, E. \& Schulman, S. (1993). Individuals in relationships: Development from infancy through adolescence. In D. C. Funder, R. Parke, C. Tomlinson-Keesey \& K. Widaman (Eds.). Studying lives through time: Personality and development, (315342). Washington DC: American Psychological Association.

Tarullo, A.R., Obradovic, J. \& Gunnar, M.R. (2009). Self- Control and the Developing Brain. Washington, DC: Zero to Three.

Teicher, M.D. (2000). Wounds That Time Won't Heal: The Neurobiology of Child Abuse. Cerebrum: The Dana Forum on brain science, 2 (4), 50-67.

Tremblay, R.E., Hartup, W.H. \& Archer, J. (Eds.) (2005). Developmental Origins of Aggression. New York: Guilford Press.

Troutman, B., Ryan, S. \& Cardi, M.A. (2000). The Effects of Foster Care Placement on Young Children's Mental Health. Protecting Children, 16 (1), 30-34.

Unger, M. (2009). The We Generation: Raising Socially Responsible Kids. Toronto, ON: McClelland \& Stewart.

Watt, N.F., Ayoub, C. Bradley, R.H. \& Puma, J.E. (Eds.) (2008). The Crisis in Youth Mental Health: Reforming the Village and Raising Our Children. Westport, CT: Praeger Perspectives.Retrieved, April 2011, from http://www.nature.com/neuro/journal/v7/n8/ abs/nn1276.html

Weiss, J.S., Wagner, S.H. (1998). What explains the negative consequences of adverse childhood experiences on adult health? Insights from cognitive and neuroscience research. American Journal of Preventive Medicine, 14, 356-360. Retrieved June 2014 from: http://www.thecapcenter.org/admin/upload/ACE\%20Cognitive\%20Neuroscience \%20Discussion.pdf

Wong, E., Wiest, D. \& Cusick, L. (2002). Perceptions of autonomy support, parent attachment, competence and self-worth as predictors of motivational orientation and academic achievement: An examination of sixth and ninth grade regular education students. Adolescence, 37 (146), 255-266. 